\title{
Radar probing of planetary regoliths: An example from the northern rim of Imbrium basin
}

\author{
Thomas W. Thompson, ${ }^{1}$ Bruce A. Campbell, ${ }^{2}$ Rebecca R. Ghent, ${ }^{2}$ B. Ray Hawke, ${ }^{3}$
} and David W. Leverington ${ }^{2,4}$

Received 25 August 2005; revised 29 December 2005; accepted 10 March 2006; published 30 June 2006.

[1] Imaging radar measurements at long wavelengths $($ e.g., $>30 \mathrm{~cm}$ ) allow deep (up to tens of meters) probing of the physical structure and dielectric properties of planetary regoliths. We illustrate a potential application for a Mars orbital synthetic aperture radar (SAR) using new Earth-based $70-\mathrm{cm}$ wavelength radar data for the Moon. The terrae on the northern margin of Mare Imbrium, the Montes Jura region, have diffuse radar backscatter echoes that are 2-4 times weaker at $3.8-\mathrm{cm}, 70-\mathrm{cm}$, and $7.5-\mathrm{m}$ wavelengths than most other lunar nearside terrae. Possible geologic explanations are (1) a pyroclastic deposit associated with sinuous rilles in this region, (2) buried mare basalt or a zone of mixed highland/basaltic debris (cryptomaria), or (3) layers of ejecta associated with the Iridum and Plato impacts that have fewer meter-sized rocks than typical highlands regolith. While radar data at $3.8-\mathrm{cm}$ to $7.5-\mathrm{m}$ wavelengths suggest significant differences between the Montes Jura region and typical highlands, the surface geochemistry and rock abundance inferred from Clementine UV-VIS data and eclipse thermal images are consistent with other lunar terrae. There is no evidence for enhanced iron abundance, expected for basaltic pyroclastic deposits, near the source vents of the sinuous rilles radial to Plato. The regions of low $70-\mathrm{cm}$ radar return are consistent with overlapping concentric "haloes" about Iridum and Plato and do not occur preferentially in topographically low areas, as is observed for radar-mapped cryptomaria. Thus we suggest that the extensive radar-dark area associated with the Montes Jura region is due to overlapping, rock-poor ejecta deposits from Iridum and Plato craters. Comparison of the radial extent of low-radar-return crater haloes with a model for ejecta thickness shows that these rock-poor layers are detected by $70-\mathrm{cm}$ radar where they are on the order of $10 \mathrm{~m}$ and thicker. A SAR in orbit about Mars could use similar deep probing to reveal the nature of crater- and basin-related deposits.

Citation: Thompson, T. W., B. A. Campbell, R. R. Ghent, B. R. Hawke, and D. W. Leverington (2006), Radar probing of planetary regoliths: An example from the northern rim of Imbrium basin, J. Geophys. Res., 111, E06S14, doi:10.1029/2005JE002566.

\section{Introduction}

[2] Radar remote sensing of planetary regoliths provides a complementary view to observations in the visible, infrared, and thermal infrared regimes. In particular, radar signals can penetrate to depths of meters to tens of meters, depending on the radar wavelength and the loss properties of the constituent materials. Understanding the upper few meters of the Martian near-surface environment will be the last great challenge in planning for future lander and sample

\footnotetext{
${ }^{1}$ Jet Propulsion Laboratory, California Institute of Technology, Pasadena, California, USA.

${ }^{2}$ National Air and Space Museum, Center for Earth and Planetary Studies, Smithsonian Institution, Washington, D. C., USA.

${ }^{3}$ Hawaii Institute of Geophysics and Planetology, University of Hawai'i, Honolulu, Hawaii, USA.

${ }^{4}$ Now at Department of Geosciences, Texas Tech University, Lubbock, Texas, USA.

Copyright 2006 by the American Geophysical Union. 0148-0227/06/2005JE002566\$09.00
}

return missions following investigations by the Mars Global Surveyor, Mars Odyssey, Mars Express, and Mars Reconnaissance Orbiter. For Mars, an orbital imaging synthetic aperture radar (SAR) could search for shallow-buried geologic features and characterize the physical and dielectric properties of regolith layers (such as the low radar reflectivity "Stealth" area [e.g., Edgett et al., 1997]) or ice deposits too deep to fully penetrate [e.g., Campbell et al., 2004]. Radar characterization of deep regolith layers is demonstrated here by a study of a highland region on the Moon.

[3] Spatially resolved Earth-based radar studies of Mars are limited to $12.6-\mathrm{cm}$ and shorter wavelengths due to the rapid spin rate of the planet and the lower available transmitted power for the Arecibo 70-cm wavelength system [e.g., Harmon et al., 1999; Muhleman et al., 1991]. The Moon, with its slower rotation rate and much smaller distance from Earth, is a better planetary target for understanding radar backscatter from a spatially varying regolith at longer wavelengths. Significant past work using $70-\mathrm{cm}$ 


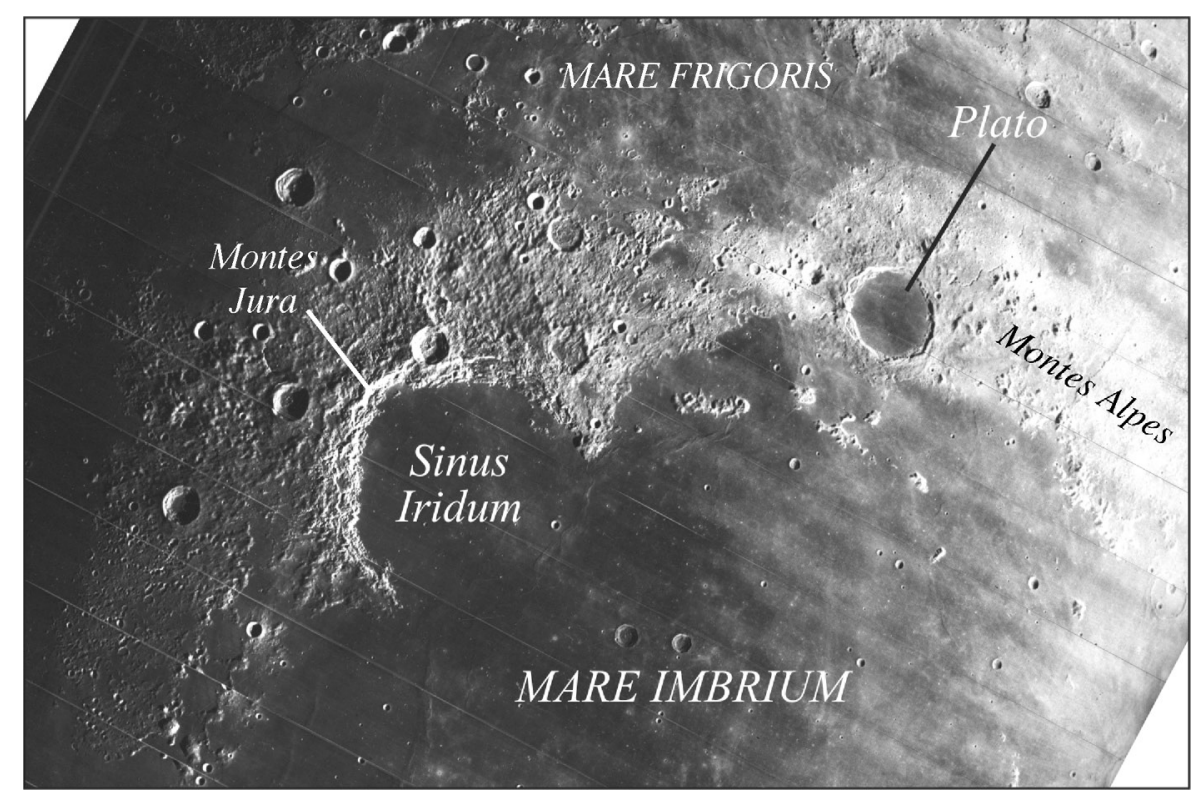

Figure 1. Lunar Orbiter IV photograph of northern Imbrium region. The Montes Jura region is located on the northern rim of Imbrium basin. The region has been modified by the large impacts that formed craters Iridum (diameter $236 \mathrm{~km}$ ) and crater Plato (diameter $101 \mathrm{~km}$ ).

radar data include studies of lunar impact crater morphology [Thompson et al., 1974], mare lava flow ilmenite content [Schaber et al., 1975; Campbell et al., 1997], and analysis of regional pyroclastic deposits [Zisk et al., 1977]. Newly acquired Arecibo 70-cm wavelength data have ten-fold higher spatial resolution (450-900 m/pixel) than those used in previous studies, permitting a much more detailed correlation of radar, spectral reflectance, and surface morphologic properties [Campbell and Hawke, 2005; Ghent et al., 2005].

[4] In this paper, we study a portion of the lunar highlands, the Montes Jura region, which surrounds the northern margin of the Imbrium basin. Gaddis et al. [1985] noted that a portion of these highlands have anomalously low $3.8-\mathrm{cm}$ radar backscatter ( $2-4$ times darker than the average terrae), and suggested the presence of a pyroclastic deposit associated with the numerous sinuous rilles in this area. The low radar backscatter associated with pyroclastic materials elsewhere on the Moon is attributed to a combination of low volume rock population and moderate-to-high microwave losses [Zisk et al., 1977]. Since those studies, a number of "cryptomaria" have been discovered, where highland material from craters or basins covers an ancient mare deposit [e.g., Mustard and Head, 1996; Schultz and Spudis, 1979]. In some cases, these areas exhibit low $70-\mathrm{cm}$ radar backscatter due to the presence of lossy mafic material within the probing depth of the signal [Campbell and Hawke, 2005; Hawke et al., 1993]. In addition, Ghent et al. [2005] showed that virtually all large Copernican-, Erathostenian-, and some Imbrian craters have low radar-return "haloes" that can be attributed to rock-poor deposits distal to the near-rim rugged ejecta.

[5] Given the broad range of possible geologic explanations for low radar returns from lunar highlands, the availability of Clementine-derived data on surface composition, and new 70-cm radar images, we re-examine the Montes Jura region. Section 2 discusses the regional geo- logic setting, and summarizes the remote sensing observations. Section 3 considers possible explanations for the radar and compositional properties and compares these with the predictions of a crater ejecta thickness model. Section 4 summarizes our conclusions and considers their implications for probing of the near-surface environment on Mars.

\section{Regional Geology and Remote Sensing Properties}

\subsection{Regional Geology}

[6] The northern boundary of the Imbrium basin is marked by an arcuate band of terrae, or highland terrain, which contains the Montes Jura, portions of the Montes Alpes, and the ejecta of Iridum and Plato craters. We refer to this area as the Montes Jura region (Figure 1). These highlands represent ejecta of the Imbrium basin-forming impact, deposited on preexisting highlands crust [Wilhelms, 1987]. Following the formation of the Imbrium basin, two large impacts formed Iridum (236-km diameter) and Plato (101-km diameter) craters. Basaltic volcanism that formed Mare Imbrium breached the rim of Iridum and flooded the crater floor, while vents within Plato buried its floor. To the north, the basalts of Mare Frigoris embay the highlands of the Montes Jura region. During the period of mare volcanism, at least some portion of the effusive activity formed sinuous rilles in the highlands, which are especially evident on the flanks of Plato crater (Figure 2) [Gaddis et al., 1985].

\subsection{Radar Properties}

[7] We have Earth-based radar images of the Montes Jura/Plato region at free-space wavelengths, $\lambda$, of $3.8 \mathrm{~cm}$ (2-3 km resolution; Figure 3) [Zisk et al., 1974], $70 \mathrm{~cm}$ (450-600 m resolution; Figure 4), and $7.5 \mathrm{~m}(10-20 \mathrm{~km}$ resolution; Figure 5) [Thompson, 1978]. A detailed description of the new 70-cm observations is given by Campbell and Hawke [2005]. 


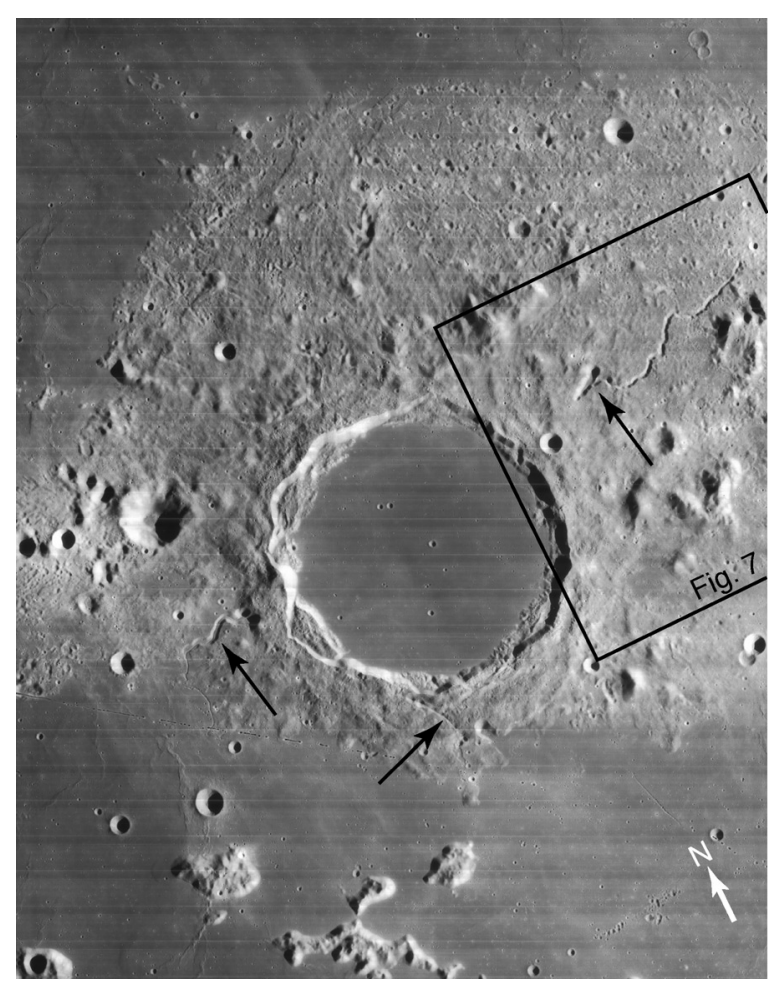

Figure 2. Lunar Orbiter IV photograph (IV-127H3) of crater Plato (101-km diameter; north at top). Arrows denote three sinuous rilles [M'Gonigle and Schleicher, 1972]; box shows location of the rilles examined in greater detail in Figure 7.

[8] The Earth-based radar data are obtained by transmitting a circularly polarized signal and receiving the echoes in the same-sense (SC, or "depolarized") and opposite-sense (OC, or "polarized") modes of circular polarization. Radar echoes from the lunar regolith are composed of inferred components due either to the large-scale (decameters or more) surface topography (which creates quasi-specular glints), or to single or multiple scattering from wavelength-sized rocks on the surface and buried within the regolith. This latter component is often termed "diffuse", and dominates the same-sense radar echo at all angles of incidence as well as the opposite-sense radar echo for angles of incidence of $30-90^{\circ}$. Since the region to the north of Imbrium was observed at radar incidence angles of $55-70^{\circ}$, the radar echoes indicate surface and near-surface rock abundances. Radar dark areas in Figures 3, 4, and 5 have fewer wavelength-sized surface and near-surface rocks; radar bright areas have more wavelength-sized surface and near-surface rocks.

[9] The lunar regolith has variable, but generally low, electrical loss, enabling the radar waves to penetrate into the subsurface. Losses due to attenuation are characterized by the loss tangent, $\tan \delta$, of the regolith mixture. The maria, with their high $\mathrm{FeO}$ and $\mathrm{TiO}_{2}$ content, have loss tangents of $\sim 0.02$ to 0.10 , and the corresponding penetration depth of radar waves is $\leq 10 \lambda$; terrae have low $\mathrm{FeO}$ and $\mathrm{TiO}_{2}$ content, loss tangents of 0.001 to 0.01 , and radar penetration depths of a few tens of $\lambda$ [Carrier et al., 1991]. Also, Earthbased infrared eclipse temperatures of the Moon (which provide a measure of surface rocks greater than $10 \mathrm{~cm}$ ) indicate that mare surfaces, on average, have more surface rocks than the terrae [Shorthill, 1973].

[10] Diffuse radar backscatter from the lunar terrae (including Imbrium basin ejecta associated with the highlands associated with Apennines and Caucasus) is typically 2-4 times that of the maria. This difference is attributed to the lower microwave loss tangent of the highland material, which allows the radar signal to propagate much farther into the regolith. As a result, an illuminating wave encounters more rocks along its total path in highland regolith, despite the lower average surface and volume rock population, than in rockier, mare-derived regoliths.

[11] The volcanic deposits of Maria Imbrium and Frigoris vary considerably in their diffuse radar echoes due to differences in the abundance of ilmenite $\left(\mathrm{FeTiO}_{3}\right)$, which is the principal cause of variations in the microwave loss tangent of mare materials [Schaber et al., 1975; Carrier et al., 1991; Campbell et al., 1997; Campbell and Hawke, 2005]. Radar-bright mare deposits have lower titanium and iron abundance, while radar-dark mare deposits have higher $\mathrm{FeO}$ and $\mathrm{TiO}_{2}$ content.

[12] However, the highlands of the Montes Jura region, in contrast to other lunar highlands, have radar returns at $3.8-\mathrm{cm}, 70-\mathrm{cm}$, and 7.5-m wavelength comparable to or weaker than those of the nearby maria (Figures 3-5). The region of low radar return extends from southwest of Sinus Iridum to east of Plato, while the lunar highlands southeast of Plato have radar backscatter properties consistent with other lunar terrae. This anomalous change in scattering properties, noted by Thompson [1978], Thompson et al. [1978], and Gaddis et al. [1985], is the motivation for further investigation.

\subsection{MultiSpectral and Thermal IR Properties}

[13] While radar data at $3.8-\mathrm{cm}$ to $7.5-\mathrm{m}$ wavelengths suggest significant differences between the Montes Jura

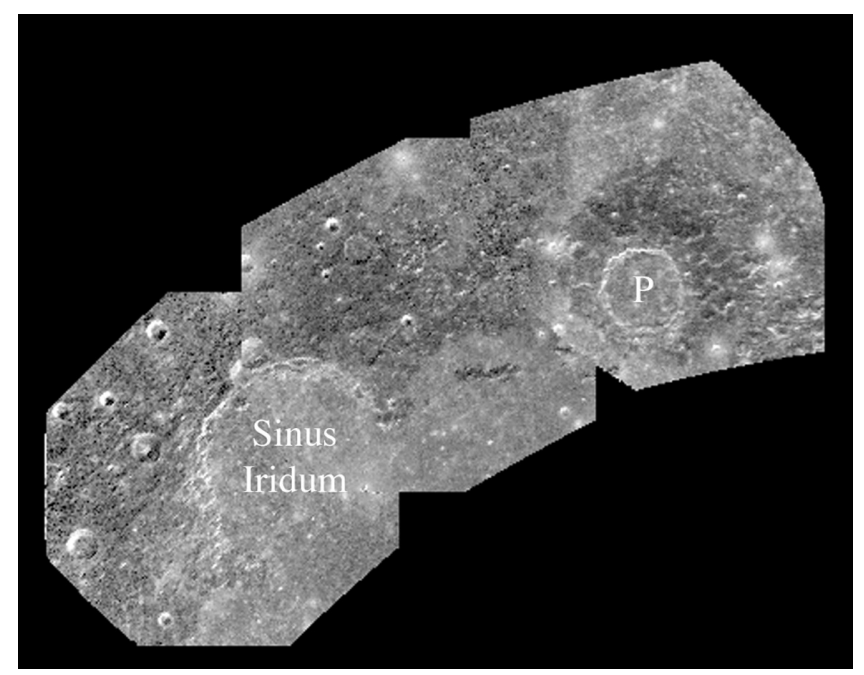

Figure 3. A 3.8-cm wavelength, same-sense (SC, depolarized) circular polarization radar image of northern Imbrium region [Zisk et al., 1974]. Spatial resolution 2$3 \mathrm{~km}$ per pixel. Note the area of low radar return associated with the Montes Jura region near Sinus Iridum and crater Plato. 


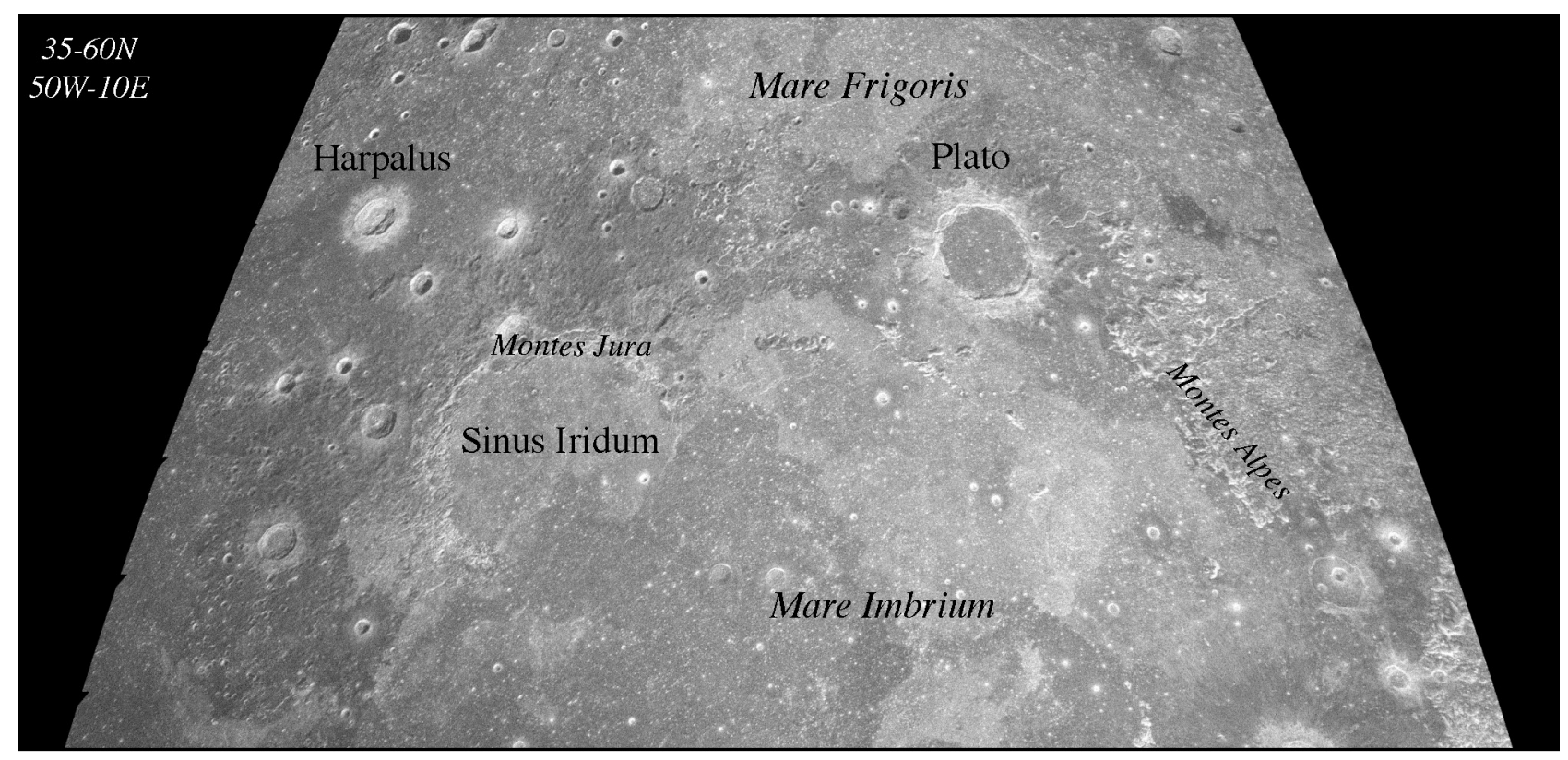

Figure 4. A 70-cm wavelength, same-sense circular (SC, depolarized) polarization radar image of northern Imbrium region $\left(35^{\circ}-60^{\circ} \mathrm{N}, 50^{\circ} \mathrm{W}-10^{\circ} \mathrm{E}\right)$. Sinusoidal projection; spatial resolution $\sim 500 \mathrm{~m}$ per pixel.

region and typical highlands, the geochemistry and rock abundance inferred from Clementine UV-VIS data and eclipse thermal images are consistent with properties of terrae across the Moon. $\mathrm{FeO}$ and $\mathrm{TiO}_{2}$ abundances based on Clementine data, using the techniques of Lucey et al. [2000a] and Gillis et al. [2003], are shown in Figures 6a and $6 \mathrm{~b}$. These $\mathrm{FeO}$ and $\mathrm{TiO}_{2}$ abundances show that the highland area from southwest of Sinus Iridum to just east of Plato has relatively homogeneous iron and titanium content, with low values of both components relative to the maria suggesting a highlands-dominated mineralogy. An optical maturity index map (Figure 6c) [Lucey et al., 2000b] shows that the Montes Jura region is characterized by mature terrain except in the rims and ejecta of the younger craters.
The infrared eclipse temperature map of Shorthill [1973] shows lower (terrae-like) surface rock abundance across Montes Jura, relative to the higher rock population in the nearby maria (Figure 6d).

\section{Possible Geologic Scenarios}

[14] There are three possible geologic scenarios for the low radar echoes associated with the Montes Jura region, based on previous studies of lunar terrae with low radar reflectivity: (1) pyroclastic mantling material [Gaddis et al., 1985; Zisk et al., 1977], (2) cryptomare deposits buried by highland material [Hawke et al., 1993; Campbell and

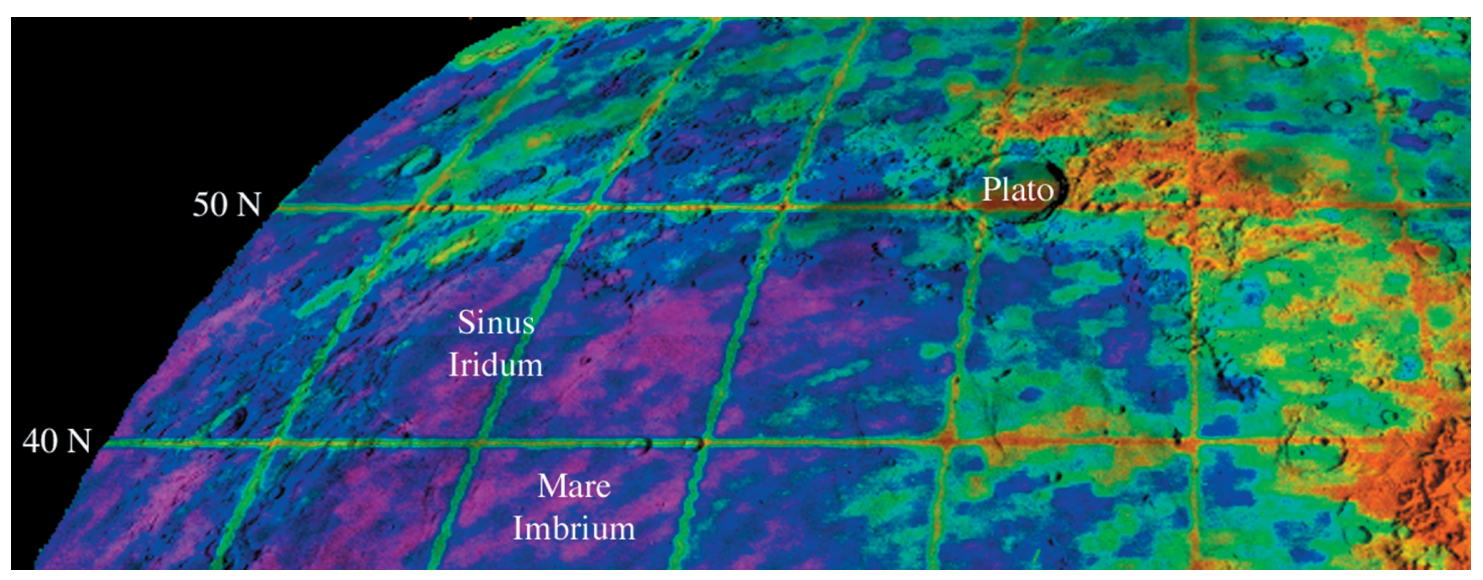

Figure 5. A 7.5-m wavelength, opposite-sense (OC, polarized) circular polarization radar image of northern Imbrium region. Spatial resolution 10-30 km [Thompson, 1978]. Orthographic projection. Color overlay of radar return on USGS shaded-relief image (lower returns are purple or blue; moderate echoes are green; high returns are red). 

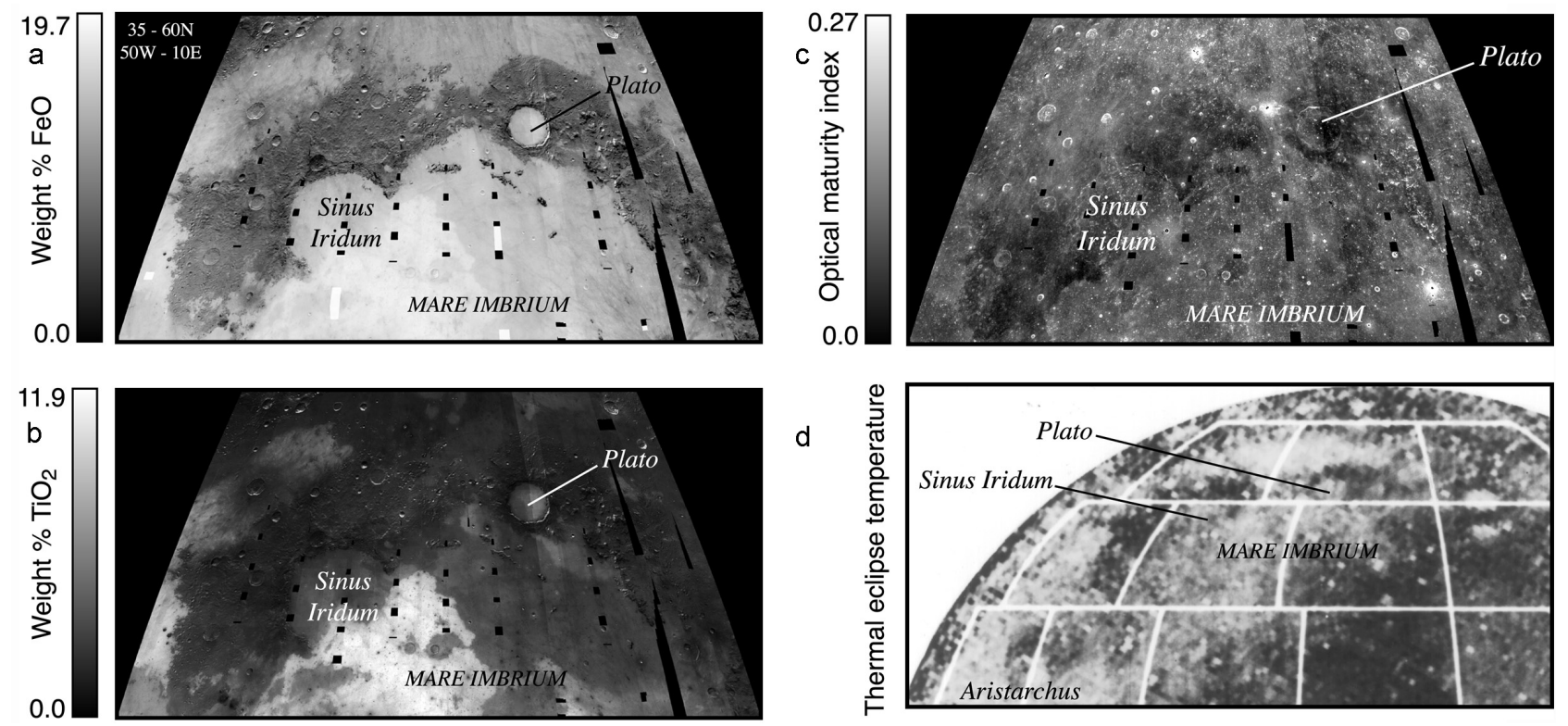

Figure 6. Maps of infrared properties derived from Clementine UV-VIS and Earth-based eclipse images. Area identical to that of Figure 4. (a) $\mathrm{FeO}$ weight percentage [Lucey et al., 2000a], (b) $\mathrm{TiO}_{2}$ weight percentage [Gillis et al., 2003], (c) optical maturity index (brighter areas denote immature terrain) [Lucey et al., 2000b], and (d) infrared eclipse image (brighter areas correspond to more surface rocks $>10 \mathrm{~cm}$ diameter) [Shorthill, 1973]. Differences in mare $\mathrm{TiO}_{2}$ content correlate with 70-cm radar scattering differences attributed to ilmenite abundance [Schaber et al., 1975; Campbell et al., 1997].

Hawke, 2005], and (3) rock-poor distal crater ejecta [Ghent et al., 2005]. We examine each of these scenarios below.

\subsection{Pyroclastic Mantling Deposits}

[15] Pyroclastic deposits on the Moon, produced by firefountaining during the early stages of mare volcanism, are typically rock-poor and have moderate to high iron content [Lucey et al., 1986]. Because of the lack of small surface rocks, as well as a possible higher loss tangent, they have low radar echoes at 3.8-cm wavelength, as described by Zisk et al. [1977] and Gaddis et al. [1985] for regional pyroclastic deposits at the Aristarchus Plateau and elsewhere. There are also low $70-\mathrm{cm}$ radar echoes in areas of relatively thick pyroclastic mantling (e.g., several meters or more) [Campbell et al., 1992]. On the basis of the low 3.8-cm radar echoes, the presence of numerous sinous rilles within the terrae, and mapping of a possible mantling deposit by M'Gonigle and Schleicher [1972], Gaddis et al. [1985] suggested that the area near Plato is mantled by "finegrained pyroclastic material of intermediate albedo."

[16] We searched for evidence of pyroclastic material within the highland regolith using geochemical information derived from model fits to the Clementine UV-VIS data. Relatively small, localized pyroclastic deposits are composed of basaltic debris with variable amounts of highland material [e.g., Hawke et al., 1989; Gaddis et al., 2003]. The techniques of Lucey et al. [2000a] and Gillis et al. [2003] can be used to determine the $\mathrm{FeO}$ and $\mathrm{TiO}_{2}$ abundances of such material. Larger, "regional" pyroclastic deposits are dominated by $\mathrm{Fe}^{2+}$-bearing glasses, black spheres, or a mixture of the two. Since these glasses and spheres were not used in deriving the algorithms of Lucey et al. [2000a] and Gillis et al. [2003], the $\mathrm{FeO}$ and $\mathrm{TiO}_{2}$ values derived for regional pyroclastics must be treated with caution. Despite this concern about the accuracy of the values, all of the identified regional pyroclastic deposits exhibit high $\mathrm{FeO}$ values [Lucey et al., 2000a]. We therefore expect that any pyroclastics of basaltic composition should at least be detected (if not accurately characterized) against a background of highland terrain.

[17] We searched for evidence of pyroclastic materials in the region using the $\mathrm{FeO}$ and $\mathrm{TiO}_{2}$ maps shown in Figures 6 and 7. The $\mathrm{FeO}$ and $\mathrm{TiO}_{2}$ values associated with the radar low surrounding Plato are similar to those of highland terrain elsewhere in the Montes Jura region. The areas around the sinuous rilles and their source vents do not exhibit enhanced $\mathrm{FeO}$ or $\mathrm{TiO}_{2}$ abundances (Figures $7 \mathrm{a}$ and $7 \mathrm{~b}$ ). Elevated $\mathrm{FeO}$ and possibly enhanced $\mathrm{TiO}_{2}$ values would be expected if these source vents produced pyroclastic mantling deposits of basaltic composition. Since elevated $\mathrm{FeO}$ values are not observed around the source vents, mafic pyroclastic deposits are not a likely explanation for the radar backscatter properties of the highlands surrounding Plato crater. While the possible pyroclastic debris with a non-mare or highland composition cannot be ruled out, it is noted that such materials have not been identified in the lunar sample collection.

\subsection{Cryptomaria}

[18] Cryptomaria are patches of basaltic material that have been buried by, or incorporated into, highland regolith created during basin or large crater formation. These areas can have lower $70-\mathrm{cm}$ and $7.5-\mathrm{m}$ radar return than typical terrae if the buried or mixed basalts have significant 

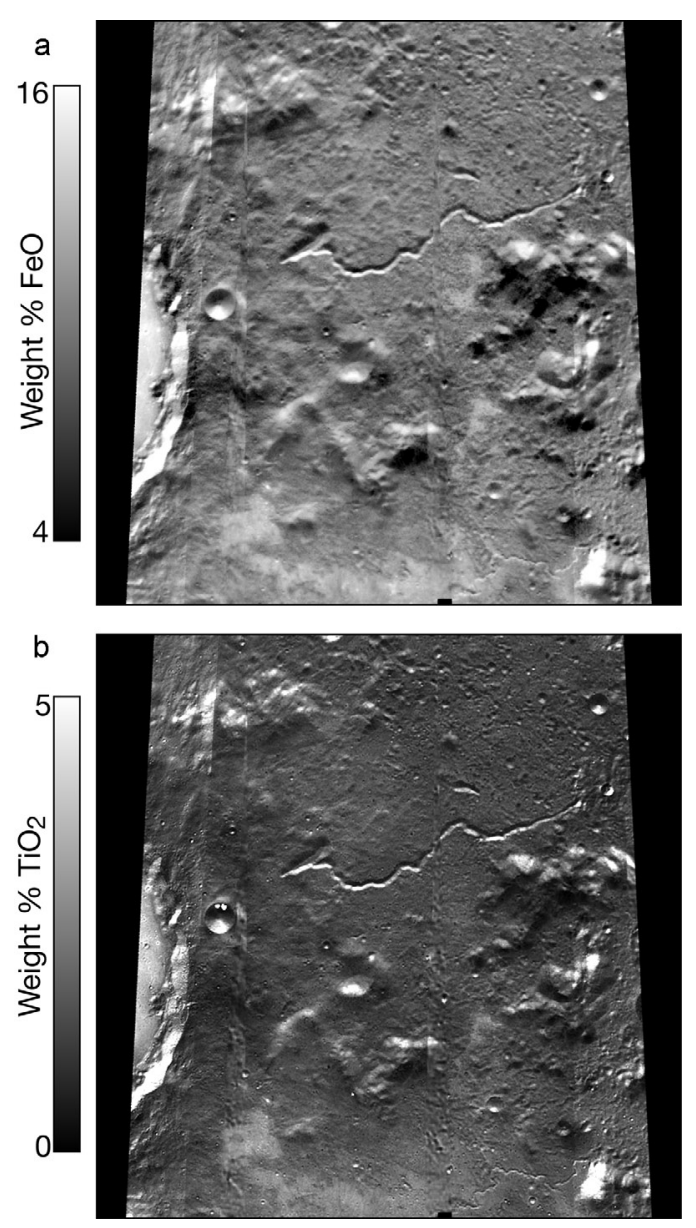

Figure 7. Clementine UV-VIS data for sinuous rilles east and northeast of Plato (location shown in Figure 2). (a) $\mathrm{TiO}_{2}$ weight percentage and (b) $\mathrm{FeO}$ weight percentage. Image size is 125 by $125 \mathrm{~km}$.

ilmenite content. For example, a large radar-dark terrae area north of Mare Humorum and west of Gassendi is attributed to a cryptomare deposit [Hawke et al., 1993]. A radar dark area in the terrae west of Oceanus Procellarum is attributed to a veneer (up to $50 \mathrm{~m}$ thick) of Orientale ejecta overlying a preexisting tongue of Oceanus Procellarum maria [Campbell and Hawke, 2005]. Other cryptomare deposits are identified on the basis of dark (in the visible) halo craters (DHCs), which excavate the nearsurface basalt, or the presence of iron and titanium enhancements in the terrae [e.g., Hawke et al., 1993; Schultz and Spudis, 1979].

[19] While topographic effects at the relatively high phase angles associated with Clementine observations of Plato can create abrupt variation in the iron and titanium maps [Robinson and Jolliff, 2002], we find no small craters with associated "ray-like" iron or titanium enhancements, and no regional changes in $\mathrm{FeO}$ or $\mathrm{TiO}_{2}$, across the Montes Jura region (Figures $6 \mathrm{a}$ and $6 \mathrm{~b}$ ). Also, there is no evidence that the areas of low radar return preferentially occupy topographically low regions bounded by features such as ridges or massifs, as is observed for cryptomaria east of Orientale [Campbell and Hawke, 2005]. Thus we conclude that cryptomare deposits do not explain the low radar echoes near Sinus Iridum and Plato.

\subsection{Rock-Poor Crater Ejecta}

[20] Radar echoes from the lunar regolith at a wavelength of $70 \mathrm{~cm}$ are modulated by the bulk loss tangent of the dust/ rock mixture and the abundance of rocks $\sim 10 \mathrm{~cm}$ and greater in diameter. In an examination of the new high-resolution 70-cm data, Ghent et al. [2005] found that Copernican-, Erathostenian-, and some Imbrian craters with diameter greater than 10-20 km have radar-dark ejecta distal to the rugged (radar-bright) near-rim terrain (Figure 8). Clementine UV-VIS data showed that these "haloes" have no strong compositional differences with the target terrain, ruling out a large shift in the bulk loss tangent of the regolith. Apollo nighttime orbital thermal measurements for a few large craters showed reduced temperatures in the radar-dark-halo regions, suggesting a rock-poor surface. It appears that crater formation on the Moon leads to distinct radial zones in the ejecta blanket, with rocky (radar-bright) near-rim ejecta surrounded by a much more comminuted (radar-dark) deposit with depth of at least several meters. Over time, smaller impacts mix the rock-poor layer with the underlying regolith, and the haloes disappear.

[21] On the basis of the lack of evidence for pyroclastic mantling material or cryptomaria across the Montes Jura region, we investigated whether the low radar returns are due to similar rock-poor ejecta from Iridum and Plato impacts. To assess this model, we address two questions: (1) Are the radial extents of the radar-dark regions, relative to the parent crater diameters, consistent with similar haloes across the nearside? (2) Is the radial extent of likely Plato and Iridum ejecta consistent with the observed radar-dark region?

[22] We first compared the radius of radar-dark haloes to the diameter of the parent crater, extending the survey of Ghent et al. [2005] to include Plato and Sinus Iridum. These data are shown in Figure 9. There is a strong correlation between the size of the crater and the extent of the radardark annulus, $r_{\mathrm{H}}$, which appears to have approximately a power law form. The halo around the relatively young crater Tycho is much larger than haloes of older craters of similar diameter, which may be due to the inclusion of short-lived, radar-dark, radial features also mapped at Aristarchus [Ghent et al., 2005]. Various authors [e.g., Moore et al., 1974; McGetchin et al., 1973] have shown that the thickness of ejecta from impact craters follows a power law form with distance from the rim, so we infer that the radius at which these haloes are first detected by $70-\mathrm{cm}$ radar corresponds to a relatively narrow range of minimum rock-poor ejecta thickness.

[23] While the particular choice of power law form for lunar crater ejecta thickness varies widely among authors, we choose one model here to illustrate the possible role of rock-poor haloes in the Montes Jura region. An estimate of ejecta thickness, $t(\mathrm{~m})$, with distance from the crater center is given by McGetchin et al. [1973]:

$$
t=8.44 \times 10^{-4} R^{0.74}\left(\frac{r}{R}\right)^{-3}
$$

where $R$ is the crater radius (m) and $r$ is the distance (m) from the center of the crater. We used (1) to determine an 


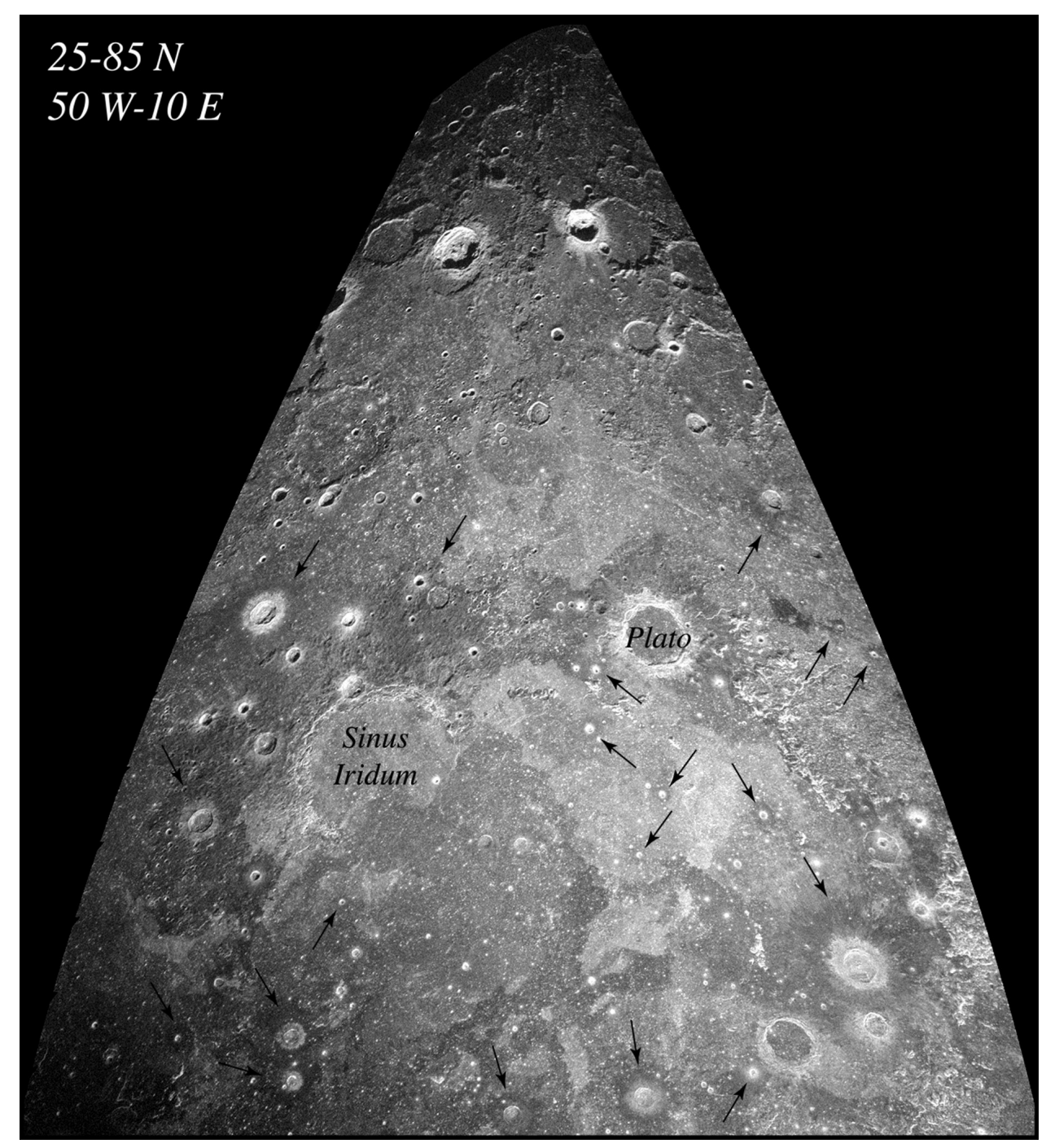

Figure 8. A 70-cm radar image of Mare Imbrium and Montes Jura region. Arrows denote radar-dark haloes associated with numerous Eratosthenian and Copernican period craters in the mare and terra.

approximate "isopach" map of the cumulative crater ejecta thickness due to Iridum, Plato, and Harpalus (Figure 10). Regions of mare material that postdate the impact events are masked (including the region surrounding Harpalus, though the contribution of Harpalus ejecta is included in the calculated cumulative thickness). This shows that Iridum and Plato ejecta dominates the upper regolith layer across the Montes Jura region to depths $>10 \mathrm{~m}$. Most of the region is covered by Iridum ejecta to depths of several tens to a few hundreds of meters. Harpalus crater (39-km diameter), which postdates Mare Frigoris, has a low-radar-return halo, but its ejecta does not contribute significantly to the total thickness across the Montes Jura region. This relatively simple approach suggests that crater ejecta dominates the near-surface regolith. Also, we use the McGetchin model to estimate the typical thickness at which rock-poor ejecta deposits are detected with the $70-\mathrm{cm}$ radar data. If we set the thickness, $t_{\mathrm{H}}$, at the outer margin of each halo, $r_{\mathrm{H}}$, to a constant value in (1), we obtain a power law of the form

$$
r_{H}=B R^{1.25}
$$

and a depth $(\mathrm{m})$ at the halo edge of

$$
t_{H}=8.44 \times 10^{-4} B^{-3}
$$

The solid line in Figure 9 shows the best fit curve for a power law exponent of the form in (2). The resulting coefficient for depth in meters, $B=0.203$, corresponds to an ejecta thickness at the radar-detected halo edge of $\sim 10 \mathrm{~m}$. Choosing a different model for ejecta thickness variations could shift this value, but it likely represents the correct order of magnitude.

[24] The presence of a large radar-dark halo surrounding Plato is also supported by comparison to lunar craters of similar size and age. Figure 11a shows the younger (Eratosthenian) crater Aristoteles (88-km diameter), which has a pronounced radar-dark halo and a radar-bright rim similar to Plato (Figure 11b). Figure 11c shows the older (Nectarian) crater Maurolycus (114-km diameter), which has no apparent radar-dark halo and a much weaker $70-\mathrm{cm}$ backscatter enhancement from its rim. In general, Nectarian-period craters tend to have less radar enhancement in their floors 


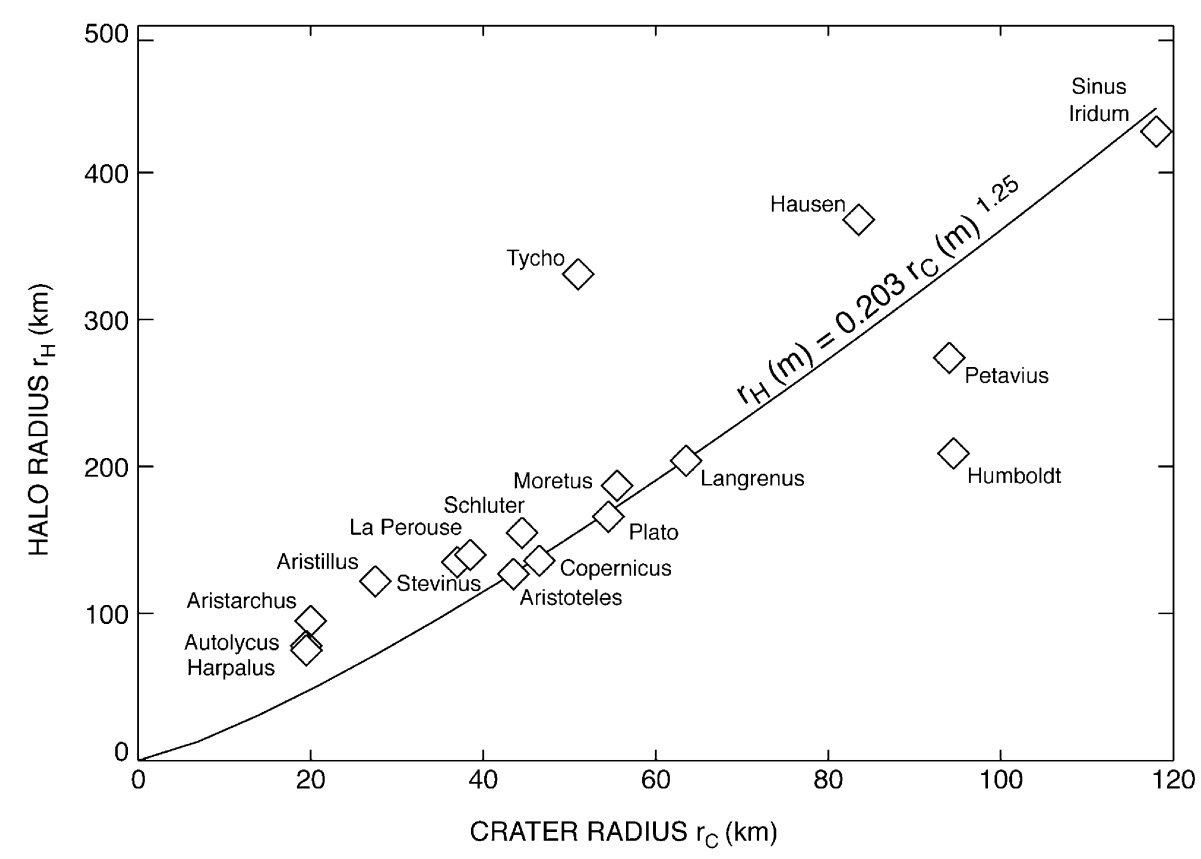

Figure 9. Crater radar-dark halo radius $r_{\mathrm{H}}$ versus crater radius $r_{\mathrm{C}}(\mathrm{km})$ for large craters on the lunar nearside [Ghent et al., 2005]. Solid line shows power law fit for a fixed exponent of 1.25 (with $r_{\mathrm{H}}$ and $r_{\mathrm{C}}$ in meters).

than Imbrian-period craters of similar size. This implies an aging process where the meter-scale floor roughness diminishes more quickly with time than the rim-related roughness. Such a sequence seems reasonable, since the rims have rugged initial topography that generates fresh mass-wasted debris for a longer period of time than is required to reduce the flat floors to average rock populations. Thus it is noted that the floor of Plato would likely

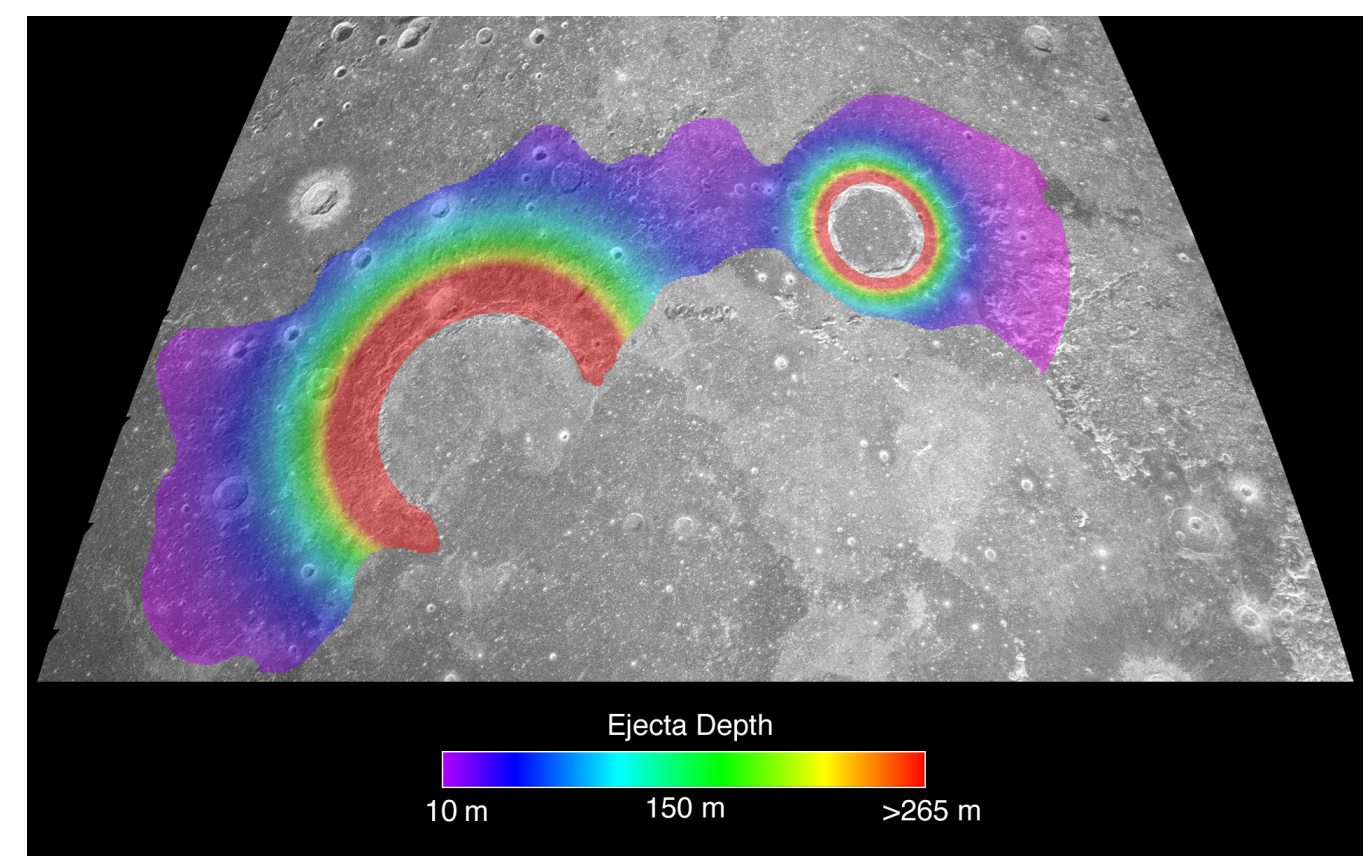

Figure 10. Isopach map of cumulative ejecta thickness in the Montes Jura region from Sinus Iridum, Plato, and Harpalus craters. Thickness based on model of McGetchin et al. [1973]. Areas covered by mare basalts that postdate Sinus Iridum and Plato are masked (including the region surrounding Harpalus). Note that the ejecta from the Iridum and Plato impact blanket the Montes Jura region to depth of tens to a few hundreds of meters. 

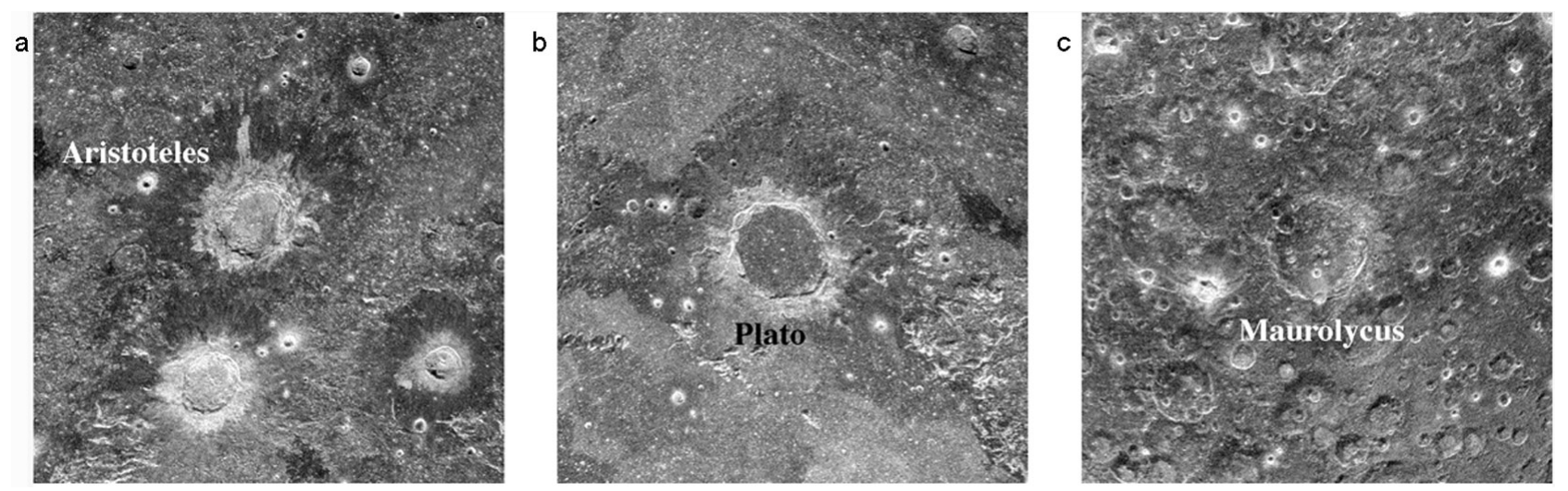

Figure 11. Three 70-cm radar images of craters spanning a range of lunar time periods: (a) Aristoteles $(88 \mathrm{~km})$, Eratosthenian period; (b) Plato $(101 \mathrm{~km})$, Upper Imbrian period; and (c) Maurolycus $(114 \mathrm{~km})$, Nectarian period. On the basis of analogies among Plato-sized craters, the floor of Plato would have a strong $70-\mathrm{cm}$ radar enhancement were it not flooded by mare basalts.

have a strong $70-\mathrm{cm}$ radar enhancement were it not flooded by mare basalts.

\section{Summary and Implications for Radar Probing of Mars}

[25] Of our initial three geologic scenarios, we can conclusively reject only the cryptomare case. The pyroclastic explanation would require a highland composition for the mantling deposits, but remains the most consistent explanation for the $3.8-\mathrm{cm}$ radar lows across the Montes Jura region. We do not observe low $3.8-\mathrm{cm}$ echoes on any other large 70-cm radar-dark haloes [Ghent et al., 2005], so these echoes remain anomalous. The deposition of concentric deposits of rock-poor ejecta by Iridum and Plato craters is our favored explanation, based on the correlation of "halo" diameters with crater radius and the absence of evidence for compositional changes in the Clementine UV-VIS data. Comparisons between these crater deposits, other radar-dark haloes on the nearside [Ghent et al., 2005], and the McGetchin et al. [1973] ejecta model show that the radar-identified radial extent of such haloes corresponds to about a $10-\mathrm{m}$ ejecta thickness. A relatively deep, rock-poor layer is also most consistent with the low $7.5-\mathrm{m}$ radar returns from the Montes Jura region (Figure 5); a thin (few meter) veneer of pyroclastic material would not likely be sufficient to produce the degree of attenuation observed at this wavelength.

[26] Figure 12 presents a cross section of the Montes Jura region, showing our interpretation of the regional geologic history. The overall topography is derived from the Imbrium basin impact, which formed as an elevated region of megaregolith ejecta on ancient crust. Ejecta from the Iridum impact covered the entire terrae west of Plato to depths of $10 \mathrm{~m}$ and more. Rock-poor, distal Iridum ejecta forms much of the 70-cm radar-dark "cover" on the Montes Jura region. Subsequent emplacement of Plato ejecta thickened the rockpoor layers over the central portion of the terrae, and extended this coverage to the east (Figure 10). Subsequent to the Iridum and Plato impacts, basaltic volcanism formed Mare Imbrium and Mare Frigoris. Some of the basalts breached the rim of Iridum crater, and volcanic eruptions flooded the floor of Plato.

[27] The northern Imbrium region of the Moon provides analogies for future radar studies of Mars. Perhaps most important is the unique information provided by significant

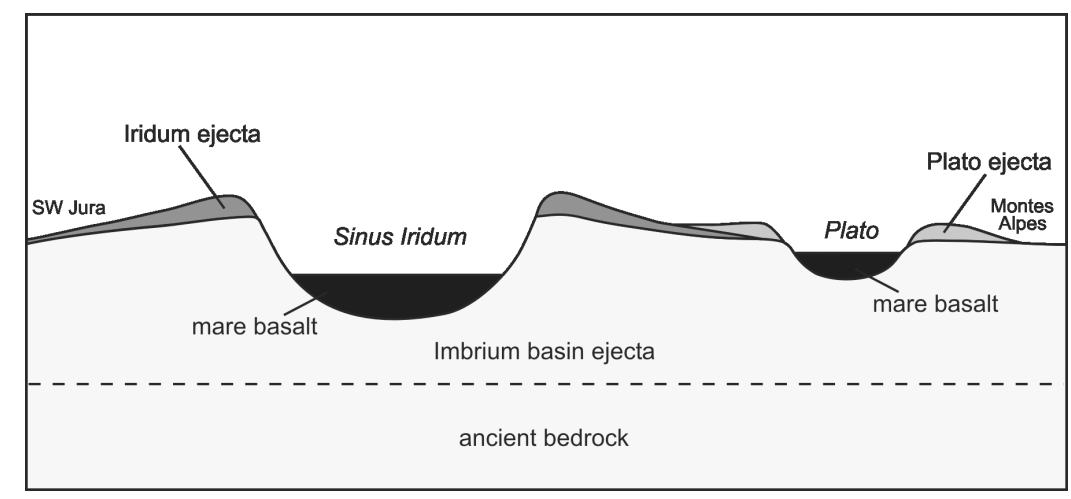

Figure 12. Schematic cross section of the Montes Jura region, showing major geologic events related to the development of the regolith. The radar, infrared, visual, and UV signatures of this region are determined primarily by the deep (tens to a few hundreds of meters) rock-poor distal ejecta of Iridum and Plato. 
penetration of the regolith. The role of crater-derived, rockpoor ejecta in the development of surface deposits across Montes Jura would be essentially unknown if observations were limited only to the UV, visual, and infrared wavelengths. It is also clear that significant information on regolith properties may be obtained even where there is no detectable basal interface (such as a lava flow). This is relevant to probing areas on Mars where mantling by aeolian, fluvial, or volcanic processes may exceed the probing depth of the radar. For example, deposits of the Medusa Fossae, or Stealth, formation might be hundreds of meters thick. Earth-based radar has already been used to map the margins of this deposit [Edgett et al., 1997], and an orbital SAR could further characterize variations in particle size across the region. Likewise, orbital radar probing of thick ice at the poles could reveal variations in loss properties due to dust contamination. Continued mapping of the Moon at 70-cm and 12.6-cm wavelengths is expected to reveal more detail on regolith processes, that in turn will aid the design of and the interpretation of the data from a Mars orbital SAR.

[28] Acknowledgments. The authors thank the staff at Cornell University, Arecibo Observatory, and the Greenbank Telescope for invaluable assistance in collecting the new $70-\mathrm{cm}$ lunar radar data. In particular, we thank D. Campbell, J. Margot, M. Nolan, and F. Ghigo. J. Chandler (SAO) provided the ephemeris files for the observations. The Arecibo Observatory is part of the National Astronomy and Ionosphere Center, which is operated by Cornell University under a cooperative agreement with the National Science Foundation (NSF) and with support from NASA. The Green Bank Telescope is part of the National Radio Astronomy Observatory, a facility of the NSF operated under cooperative agreement by Associated Universities, Inc. The authors thank Paul Spudis and an anonymous reviewer for insightful comments. This work was supported in part by grants from the NASA Planetary Geology and Geophysics Program. Research by one of us (T.W.T.) was carried out at the Jet Propulsion Laboratory, California Institute of Technology, and was sponsored by the National Aeronautics and Space Administration.

\section{References}

Campbell, B. A., and B. R. Hawke (2005), Radar mapping of lunar cryptomaria east of Orientale basin, J. Geophys. Res., 110, E09002, doi:10.1029/2005JE002425.

Campbell, B. A., N. J. Stacy, D. B. Campbell, S. H. Zisk, and T. W. Thompson (1992), Estimating lunar pyroclastic deposit depths from imaging radar data: Applications to lunar resource assessment, in Workshop on New Technologies for Lunar Resource Assessment, LPI Tech. Rep. 9206, pp. 16-17, Lunar and Planet. Inst., Houston, Tex.

Campbell, B. A., B. R. Hawke, and T. W. Thompson (1997), Longwavelength radar studies of the lunar maria, J. Geophys. Res., 102, 19,307-19,320.

Campbell, B. A., T. A. Maxwell, and A. Freeman (2004), Mars orbital synthetic aperture radar: Obtaining geologic information from radar polarimetry, J. Geophys. Res., 109, E07008, doi:10.1029/2004JE002264.

Carrier, W. D., G. R. Olhoeft, and W. Mendell (1991), Physical properties of the lunar surface, in Lunar Sourcebook, edited by G. H. Heiken, D. T. Vaniman, and B. M. French, pp. 475-594, Cambridge Univ. Press, New York.

Edgett, K. S., B. J. Butler, J. R. Zimbelman, and V. E. Hamilton (1997), Geologic context of the Mars radar "Stealth" region in southwestern Tharsis, J. Geophys. Res., 102, 21,545-21,568.

Gaddis, L. R., C. M. Pieters, and B. R. Hawke (1985), Remote sensing of lunar pyroclastic mantling deposits, Icarus, 61, 461-489.

Gaddis, L. R., M. I. Staid, J. A. Tyburczy, B. R. Hawke, and N. E. Petro (2003), Compositional analyses of lunar pyroclastic deposits, Icarus, 161, $262-280$.

Ghent, R. R., D. W. Leverington, B. A. Campbell, B. R. Hawke, and D. B. Campbell (2005), Earth-based observations of radar-dark crater haloes on the Moon: Implications for regolith properties, J. Geophys. Res., 110, E02005, doi:10.1029/2004JE002366.
Gillis, J. J., B. L. Jolliff, and R. C. Elphic (2003), A revised algorithm for calculating $\mathrm{TiO}_{2}$ from Clementine UVVIS data: A synthesis of rock, soil, and remotely sensed $\mathrm{TiO}_{2}$ concentrations, J. Geophys. Res., 108(E2), 5009, doi:10.1029/2001JE001515.

Harmon, J. K., R. E. Arvidson, E. A. Guinness, B. A. Campbell, and M. A. Slade (1999), Mars mapping with delay-Doppler radar, J. Geophys. Res., 104, 14,065-14,090.

Hawke, B. R., C. R. Coombs, L. R. Gaddis, P. G. Lucey, and P. D. Owensby (1989), Remote sensing and geologic studies of localized dark mantle deposits on the Moon, Proc. Lunar Planet. Sci. Conf. 19th, 255-268.

Hawke, B. R., C. A. Peterson, P. G. Lucey, G. J. Taylor, D. T. Blewett, B. A. Campbell, and P. D. Spudis (1993), Remote sensing studies of the terrain northwest of Humorum Basin, Geophys. Res. Lett., 20, 419-422.

Lucey, P. G., B. R. Hawke, C. M. Pieters, J. W. Head, and T. B. McCord (1986), A compositional study of the Aristarchus region of the Moon using near-infrared reflectance spectroscopy, Proc. Lunar Planet. Sci. Conf. 16th, Part 2, J. Geophys. Res., 91, suppl., D344-D354.

Lucey, P. G., D. T. Blewett, and B. L. Jolliff (2000a), Lunar iron and titanium abundance algorithms based on final processing of Clementine UV-Visible images, J. Geophys. Res., 105, 20,297-20,306.

Lucey, P. G., D. T. Blewett, G. J. Taylor, and B. R. Hawke (2000b), Imaging of lunar surface maturity, J. Geophys. Res., 105(E8), 20,37720,386 .

M'Gonigle, J. W., and D. Schleicher (1972), Geologic map of the Plato quadrangle of the Moon, U.S. Geol. Surv. Misc. Geol. Invest. Ser., Map I-701.

McGetchin, T. R., M. Settle, and J. W. Head (1973), Radial thickness variations in impact crater ejecta: Implications for lunar basin deposits, Earth Planet. Sci. Lett., 20, 226-236.

Moore, H. J., C. A. Hodges, and D. H. Scott (1974), Multiringed basinsillustrated by Orientale and associated features, Proc. Lunar Sci. Conf. 5 th, $71-100$.

Muhleman, D. O., B. J. Butler, A. W. Grossman, and M. A. Slade (1991), Radar images of Mars, Science, 253, 1508-1513.

Mustard, J. F., and J. W. Head (1996), Buried stratigraphic relationships along the southwestern shores of Oceanus Procellarum: Implications for early lunar volcanism, J. Geophys. Res., 101, 18,913-18,925.

Robinson, M. S., and B. L. Jolliff (2002), Apollo 17 landing site: Topography, photometric corrections, and heterogeneity of the surrounding highland massifs, J. Geophys. Res., 107(E11), 5110, doi:10.1029/ 2001JE001614.

Schaber, G. G., T. W. Thompson, and S. H. Zisk (1975), Lava flows in Mare Imbrium: An evaluation of anomalously low Earth-based radar reflectivity, Moon, 13, 395-423.

Schultz, P. H., and P. D. Spudis (1979), Evidence for ancient mare volcanism, Proc. Lunar Planet. Sci. Conf. 10th, 2899-2918.

Shorthill, R. W. (1973), Infrared atlas charts of the eclipsed Moon, Moon, 7, $22-45$.

Thompson, T. W. (1978), High resolution lunar radar map at $7.5 \mathrm{~m}$ wavelength, Icarus, 36, 174-188.

Thompson, T. W., H. Masursky, R. W. Shorthill, G. L. Tyler, and S. H. Zisk (1974), A comparison of infrared, radar and geologic mapping of lunar craters, Moon, 10, 87-117.

Thompson, T. W., T. V. Johnson, D. L. Matson, R. S. Saunders, R. W. Shorthill, S. H. Zisk, H. J. Moore, and G. G. Schaber (1978), Unusual remote sensing signatures of Montes Jura and crater Plato, Lunar. Planet. Sci., IX, 1164-1165.

Wilhelms, D. E. (1987), The geologic history of the Moon, U.S. Geol. Surv. Prof. Pap., 1348.

Zisk, S. H., G. H. Pettengill, and G. W. Catuna (1974), High-resolution radar maps of the lunar surface at 3.8-cm wavelength, Moon, 10, 17-50.

Zisk, S. H., C. A. Hodges, H. J. Moore, R. W. Shorthill, T. W. Thompson, E. A. Whittaker, and D. E. Wilhelms (1977), The Aristarchus-Harbinger region of the Moon: Surface geology and history from recent remotesensing observations, Moon, 17, 59-99.

B. A. Campbell and R. R. Ghent, National Air and Space Museum, Center for Earth and Planetary Studies, Smithsonian Institution, MRC 315, P.O. Box 37012, Washington, DC 20013-7012, USA. (campbellb@si.edu; ghentr@si.edu)

B. R. Hawke, Hawaii Institute of Geophysics and Planetology, University of Hawai'i, 1680 East-West Road, Honolulu, HI 96822, USA. (hawke@ higp.hawaii.edu)

D. W. Leverington, Department of Geosciences, Texas Tech University, Box 41053, Lubbock, TX 79409-1053, USA. (david.leverington@ttu.edu)

T. W. Thompson, Jet Propulsion Laboratory, California Institute of Technology, 4800 Oak Grove Drive, Mail-Stop 300-227, Pasadena, CA 91109-8099, USA. (thomas.w.thompson@jpl.nasa.gov) 